\title{
Explaining the past with ABM: On modelling philosophy
}

\author{
M. W. Lake ${ }^{1}$ \\ UCL Institute of Archaeology \\ 31-34 Gordon Square \\ London WC1H OPY
}

\begin{abstract}
2013
Final revised manuscript for publication in Wurzer, Kowarik \& Reschreiter eds, Agent-based Modeling and Simulation in Archaeology, Springer

${ }^{1}$ mark.lake@ucl.ac.uk
\end{abstract}


This chapter discusses some of the conceptual issues surrounding the use of agent-based modelling in archaeology. Specifically, it addresses three questions: Why use agent-based simulation? Does specifically agent-based simulation imply a particular view of the world? How do we learn by simulating? First, however, it will be useful to provide a brief introduction to agent-based simulation and how it relates to archaeological simulation more generally. Some readers may prefer to return to this chapter after having read a more detailed account of an exemplar (chapter 2) or of the software technology (chapter 4). Textbooks on agent-based modelling include Grimm and Railsback 2005 and Railsback and Grimm 2012, both aimed at ecologists, the rather briefer Gilbert 2008, aimed at sociologists, and Ferber 1999, which treats agent-based simulation from the perspective of artificial intelligence and computer science.

\section{Agent-based modelling in archaeology}

Agent-based modelling (ABM) is a method of computer simulation that is particularly well suited to exploring how the aggregate characteristics of some system arise from the behaviour of its parts. The parts in question are modelled as 'agents', that is, units which have causal efficacy and can reasonably be treated as individuals in the sense that they act as cohesive wholes in respect of the particular research problem. Agents are usually situated in an artificial environment and their behaviour is governed by rules which specify how they respond to the content of that environment and possibly also the behaviour of other agents (Epstein and Axtell 1996, p.5).

The well known Long House Valley agent-based model (chapter 2; Dean et al. 2000; Axtell et al. 2002; also Kohler et al. 2005 for a popular account) illustrates the paradigmatic features of a typical agent-based model. The Long House Valley ABM was built to explore the relationship between climatically determined resource availability, settlement location and population growth in Long House Valley, Arizona in the period A.D. 400-1450. In this example the agents are individual Puebloan households, each of which use rules to choose where to settle in Long House Valley in order to grow sufficient maize to survive. The maize-growing potential for each hectare in the valley was inferred from painstaking palaeoenvironmental research and is input into the model for every year from A.D. 400 to 1450. When the simulation is run, growth of a household and/or environmental degradation can lead to fissioning or wholesale relocation of that settlement. In this way, repeated individual household decision-making and reproduction produces a changing macro-level settlement pattern and population size, both of which could be compared with the archaeological evidence. After experimenting with different assumptions concerning the productivity of prehistoric maize 
and the fertility and longevity of households, the authors concluded that climate change alone is insufficient to explain the eventual abandonment of Long House Valley.

The Long House Valley agents fulfil the standard textbook requirement (e.g. Ferber 1999, pp.9-10) that agents should be autonomous (directed by their own goals), goal-directed (behave in an attempt to achieve their goals), reactive (change their behaviour in response to the properties of the environment) and - usually - situated (have an explicit location in the environment). It is, however, possible to add additional complexity designed to make agents more human-like. Thus Ferber (1999) notes that agents may additionally maintain a representation of their world and thus be capable of cognition, be social in the sense of interacting with and in particular maintaining patterned interaction with other agents, and be capable of reproduction involving some kind of recombination or mutation of their attributes. All of these 'extensions' have in fact been implemented in archaeological agent-based models, in some cases more than 20 years ago. Thus, for example, Mithen (1990) and Lake's (2000) agent-based models of Mesolithic hunter-gatherer foraging very explicitly model agents learning about their environment and using the information so gained to inform their decision-making; in the case of Lake's model this extends to each agent having a geographically referenced cognitive map of its environment. Both these models rely on agents having memory, but in another case the capacity and longevity of agent memory was itself the subject of enquiry (Costopoulos 2001). Similarly, a number of archaeological agent-based models have incorporated aspects of social interaction, ranging from inter-agent social learning (Kohler et al. 2012b; Lake 2000; Mithen 1989; Premo 2012; Premo and Scholnick 2011) through simple collective decision-making (Lake 2000) to exchange (Bentley et al. 2005; Kobti 2012), group formation (Doran et al. 1994; Doran and Palmer 1995) and the emergence of leaders (Kohler et al. 2012b). Agent reproduction involving recombination or mutation of attributes can also be found in archaeological agent-based models, including Kachel et als' (2011) evaluation of the so-called 'grandmother hypothesis' for human evolution, Lake's (2001b) model of the evolution of the hominin capacity for cultural learning and Xue et als' (2011) model of the extent to which achieving a high degree of adaption to the environment can be detrimental in the long term.

As well as making agents more human-like, it is also possible to extend a paradigmatic agent-based model by explicitly modelling feedback between agent behaviour and the properties of the environment in which the agents are situated. In a very simple agent-based model the environment might be completely unchanging. This was not the case in the Long House Valley model, since that model explicitly included external environmental forcing by altering the maize yield over time in accordance with the palaeoclimatic reconstruction. Other archaeological agent-based models make the envi- 
ronment even more dynamic by, for example, explicitly modelling resource degradation as a result of agent activity. One of the first models to achieve this was the first (mid 1990's) version of Kohler et als' Village ABM, which explicitly incorporated reduced yields from continued farming (2000; 2012a). More recent versions of the Village ABM also explicitly model the population growth of prey species such as deer (Johnson and Kohler 2012). Unsurprisingly, some of the most sophisticated modelling of environmental change is to be found in agent-based models conceived as part of the growing programme of 'socionatural' studies (McGlade 1995; van der Leeuw and Redman 2002; Kohler and van der Leeuw 2007a) of the socioecological (Barton et al. 2010a) dynamics of long-term human environment interaction. At present there is a concerted effort to further this agenda by coupling agent-based models of human behaviour with established geographical information systems or other raster models of natural processes such as soil erosion (e.g. Barton et al. 2010b,a; Kolm and Smith 2012).

I have recently provided an up-to-date review of the use of computer simulation in archaeology (Lake 2013), which includes detailed discussion of the vicissitudes and subject matter of archaeological agent-based modelling. For the purposes of this chapter it is worth drawing out three main points. The first is that archaeologists have used simulation models that exhibit many of the characteristics of agent-based models for almost as long as they have used computers, and certainly long before adoption of the term 'agent-based model' in the 1990s. Wobst considered that the approach taken in his 1974 computer simulation model of Palaeolithic social systems could "best be conceptualized as an educational game consisting of a gaming table (area), pieces (people), rules (biological or cultural rules of behavior), and a series of different outcomes depending on the specifications of the components" (Wobst 1974, p.158); clearly, we would now call this an agent-based model, as Wobst has himself noted (2010, p.9). Thomas' (1972) model of Shoshonean subsistence also exhibits some of the characteristics of an agent-based model (particularly in its implementation of a spatially heterogeneous environment) and Wright and Zeder's 1977 simulation model of linear exchange is another that could be considered to be an early agent-based model (Doran 2000, p.90). Mithen's late 1980s simulation model of Mesolithic hunter-gather decision-making (Mithen 1987, 1990) is perhaps the most recent well-known agent-based simulation model that was not explicitly labelled as such. Even recent textbooks on ABM now acknowledge that "agent-based modelling is no longer a completely new approach" (Railsback and Grimm 2012, p.11), but they also note the potential advantage that "the worst mistakes have been made and corrected" (ibid.). This, of course, will only be true if new modellers drawn in by ever more user-friendly software make the effort to acquaint themselves with earlier agent-based models and avoid naively re-inventing the wheel.

The second point that can be drawn from my review of archaeological 
simulation is that, although something like agent-based modelling has been used in archaeology for 40 years, there has unquestionably been an explosion of interest in the technique since the turn of the millennium. Kohler and Gumerman's (2000) influential collection of agent-based models, Dynamics in Human and Primate Societies, heralded the arrival in archaeology of fully modern and self-identified agent-based simulation. The influence of modern agent-based modelling on the resurgence of archaeological interest in computer simulation more generally can not be overstated: over $50 \%$ of the c. 70 substantive archaeological simulation models published between 2001 and March 2013 are agent-based models (Lake 2013). These models differ widely in complexity, ranging from those that barely meet the minimum textbook definition of an agent-based model, but were implemented using the computational framework provided by an agent-based simulation toolkit (e.g. Bentley et al. 2004), through relatively simple abstract models that are however unquestionably agent-based (e.g. Premo 2007), to much more complex realistic models that exhibit many of the optional attributes discussed above (e.g. Kohler et al. 2012a; Wilkinson et al. 2007).

A final point to make about the status of agent-based modelling in archaeology is that it can now be argued to have acquired a degree of methodological maturity (Lake 2013). First, a high proportion of recent publications reporting simulation results do not foreground the method itself, or at the very least they balance the account of method with a substantive research conclusion. The latter point provides the second line of evidence that simulation has finally come of age as part of the archaeological toolkit: that archaeological simulation models increasingly provide results that are useful to researchers who were not involved in the modelling process (i.e. they have what Innis 1972, p.34 referred to as "output utility"). That said, it is also clear that agent-based modelling is by no means evenly distributed across all areas of archaeological enquiry, but is largely concentrated in the study of human evolution, evolutionary archaeology and the aforementioned area of socionatural studies. Furthermore, these areas are in turn differentiated by the extent to which they favour relatively simple models offering a high level of abstraction (typical of human evolution and evolutionary archaeology) or more complex models offering greater realism (typical of socionatural studies), an issue to which I will return.

\section{Why agent-based modelling?}

As just discussed, there has been a resurgence of interest in the application of computer simulation to archaeological problems, and agent-based models account for over half of all archaeological computer simulation undertaken in the new millennium. Even if this burgeoning activity reflects increased acceptance of the general case for using computer simulation - of whatever 
kind - in archaeology, it is very likely to have been triggered by the conceptual accessibility of agent-based modelling and/or the sense that agent-based modelling is part of a scientific paradigm that aligns well with contemporary archaeological interests. Each of these reasons for the growth of agent-based modelling is discussed in turn.

\subsection{The general case for computer simulation in archaeology}

The case for using computer simulation in archaeology has been well-rehearsed (e.g. initially in Doran 1970 and more recently in Kohler 2000 and Premo et al. 2005) and has four main strands: enforcing conceptual clarity in the interest of 'doing science', helping understand how things change, helping infer past behaviour from a static archaeological record, and testing other quantitative methods.

The case for computer simulation starts with the observation that archaeologists routinely build models, that is " pieces of machinery that relate observations to theoretical ideas" (Clarke 1972, p.2). As Kohler and van der Leeuw (2007a, p.3) remind us, even informal explanations for "how" or "why" something happened in the past are in fact models. Of course, some models are more formal than others, although even formal models vary greatly in their means of expression, ranging from, for example, the material replica of an Iron Age roundhouse through algorithmic specification of hunter-gatherer decision-making to the use of coupled differential equations to study the rise of urbanism. The advantage of formal modelling is that, by making explicit and unambiguous the relationships between the things in the model and also the intended scope of the model, it is easier to determine whether the model is supposed to be applicable to some observed phenomenon and, if so, whether it adequately predicts or fits it. This in turn facilitates the pursuit of archaeology as a science, whether one wishes to test a hypothesis in accordance with the hypothetico-deductive framework of the New Archaeology (Watson et al. 1971), or explore the utility of a model in a manner more consistent with contemporary model-based science (see Kohler and van der Leeuw 2007a, p.3 for a manifesto; also commentary in section 4). Thus one of the most important benefits of computer simulation is simply that in order to implement a model as a computer programme it must be very precisely specified in mathematical or algorithmic terms (Doran 1970, p.298). If the modeller learns something from this process then the simulation can be said to have "conceptual utility" (Innis 1972, p.33) because it has served to "create new problems and view old ones in new and interesting ways" (Zubrow 1981, p.143). Of course, actually solving problems requires an appropriate inferential strategy (Premo 2007), as discussed in section 4.1.

While computer simulation models may be among the most formal and least ambiguous of all kinds of model, the characteristic which sets them apart from other kinds of models is, of course, that they are iterative (Clarke 
1972, p.2). One should, however, distinguish between iterative models in general (numerical models) and simulation models in particular (see Lake 2001a, p.723-4 for more detailed discussion). Numerical modelling is often used to obtain an approximate solution to some analytically intractable mathematical model which has been designed to predict the equilibrium state of a system, but without any interest in how it came about (for example an optimal subsistence strategy, as per e.g. Belovsky 1987). In contrast, simulation models are explicitly concerned with the passage of time and the state of the system changes by a process that is in some way analogous to the process of change in the real world (Doran and Hodson 1975, p.286 and Renfrew 1981, pp.292-3). This explicit modelling of process is important for two reasons.

First, computer simulation subtly shifts the focus of modelling from asking "how it works" to "how it got to be as it [was]" (Allen and McGlade 1987, p.724). In this, simulation better aligns formal modelling with modern understanding of the importance of non-linearity, recursion and noise in the evolution of living systems, whether that is couched in the language of chaos (Schuster 1988), complexity (Waldrop 1992), niche construction (Odling-Smee et al. 2003), structuration (Giddens 1984), evolutionary drive (Allen and McGlade 1987) or contingency (Gould 1989). Thus, to pick just three examples of explicit concern with past dynamics, archaeologists have built non-linear dynamical systems models to investigate the likelihood of instability in European Bronze Age exchange systems (McGlade 1997), and agent-based models to explore cyclical nucleation and dispersion in Jomon settlement (Crema 2013) and the optimal adaptive fit to environments punctuated by rapid reversals (Xue et al. 2011).

Second, and related, the focus of simulation on process fits well with the notion that archaeology has as much or more to offer contemporary society as a science of long-term societal change and human-environment interaction than it does as a provider of ethnographic-scale snapshots of the past. While the latter can usefully challenge us to recognise the diversity of human lifeways, it is only by studying processes that one can explain why particular lifeways obtained in particular circumstances. Furthermore, understanding the processes that drive social change and environmental adaptation affords the possibility of predicting how contemporary lifeways might evolve in the future, especially if one studies such processes in the spirit that "history is still running" (Allen et al. 2006, p.2). Archaeologists working under the banner of socionatural studies are particularly conscious of this last point and have forcefully made the case for "an enhanced role for archaeologists in the study of contemporary environmental issues" (van der Leeuw and Redman 2002, abstract), even going so far as to suggest that modern archaeology has the potential to be "at the center of modern studies of long-term global change" (van der Leeuw 2008, p.477). The intellectual antecedents of this agenda can be found in Leslie White's interest in the long-term evolution 
of energy capture and Julian Steward's awareness that environmental adaptation is mediated through material culture and knowledge (Kohler and van der Leeuw 2007a, p.11), but the contemporary approach is augmented with more sophisticated understanding of the nature of change in complex systems, one which rejects the a priori assumption of a unilineal trajectory and which can now be better pursued through advances in computer simulation (see Barton 2013 for a recent manifesto and Kohler and Varien 2012 for the history and role of simulation in one long-running socionatural study).

While computer simulation helps archaeologists study how processes of social and environmental change unfold, and thus contributes to archaeology as a human science uniquely equipped to study long-term change in socionatural systems, it also contributes to the more specifically archaeological problem of inferring what specific processes, that is, behaviour, produced the observed archaeological evidence. Binford (1981) long ago made the argument that archaeologists must infer past dynamics (behaviours) from a static archaeological record and, of course, the usual means of doing this is to compare patterns in the archaeological evidence with those expected from the candidate behaviour. As Kohler et al. (2012a, p.40) remind us, archaeologists usually make the connection between a particular behaviour and an expected archaeological pattern on the basis of "intuition or common sense, ethnographic analogies and environmental regularities, or in some cases experimental archaeology", but computer simulation offers anothersometimes the only - way of doing this. For example, Mithen's $(1988 ; 1990)$ computer simulation of Mesolithic hunting goals generated a virtual faunal assemblage whose species composition could then be compared with the archaeological record. In similar vein, Premo's (2005) simulation of Pleistocene hominin food sharing created virtual assemblages which revealed that the dense artifact accumulations at Olduvai and Koobi Fora, long attributed to central place foraging, could alternatively have been formed by routed foraging in a patchy environment. These two examples demonstrate the advantage of adding computer simulation to the archaeologist's inferential toolkit: not only that it forces us to codify and make explicit our assumptions, but that it also allows us to explore the outcome of behaviours which can no longer be observed and for which there is no reliable recent historical record. In addition, it allows us to explore the outcome of behaviour aggregated at the often coarse grained spatial and temporal resolution of the archaeological record.

The last point, that the archaeological record provides only a-often sparse - sample of the outcome of whatever behaviour generated it, leads to another well established archaeological use of computer simulation, which is not to directly infer the past behaviour in question, but to test the efficacy of other methods of analysis. The role of such 'tactical' simulations is to provide data whose origin is understood in order to test the inferential power of the analytical technique in question (Orton 1982). Examples to date 
include tests of measures of the quantity of pottery (ibid.), multivariate statistics (Aldenderfer 1981), cladistic methods (Eerkens et al. 2005) and the relationship between temporal frequency distributions and prehistoric demography (Surovell and Brantingham 2007).

\subsection{The conceptual accessibility of agent-based modelling}

It can be argued that specifically agent-based modelling is more accessible than other forms of computer simulation for both technical and conceptual reasons. The technical (i.e. computer science / software) dimension of agentbased modelling is discussed in chapters 4,7 and 8 , so here I focus on four ways in which agent-based modelling can be considered conceptually more accessible than other forms of computer simulation (such as dynamical systems modelling). Two of these concern the description of rules and outputs, and the other two concern what can be modelled.

First, it seems appropriate to start this discussion with the output of agent-based modelling, since that probably influences how agent-based modelling is perceived in the wider community. While it is true that the initial output from an agent-based model can be quite undigestable, comprising nothing more than many thousands of lines of a numerical log, it can beand often is - visually attractive and, in particular, comprehensible in commonsense terms. At one extreme, it is now possible to integrate agent-based modelling with virtual reality so as to produce a photorealistic rendering of agents moving through a reconstructed palaeolandscape. This has been demonstrated for an agent-based simulation of Mesolithic hunter-gatherers foraging in a landscape that is now submerged under the North Sea (Ch'ng 2007; Ch'ng et al. 2011) and, while it is not clear what data is recorded for more conventional analysis, there is no doubt that this kind of realism captures the imagination of the public and less quantitatively inclined archaeologists alike. More common, however is two-dimensional mapping, for example, of the location of households presented as a series of snapshots at fixed intervals (e.g. Kohler et al. 2005, p.79), the path followed by an individual agent (e.g. Costopoulos 2001, Fig.9), or the distribution of artefacts discarded by agents (e.g. Lake 2000, Fig.7). In my experience, nonspecialists find the spatial patterns often output by agent-based simulations more readily comprehensible than the purely temporal patterns output by other methods such as dynamical systems models (perhaps with the exception of population curves, such as those found in Kohler et al. 2012a). Moreover, the conclusions of dynamical systems models are often supported by phase portraits and phase diagrams (e.g. McGlade 1997), both of which assume a facility with mathematical abstraction that is not widespread among conventionally trained archaeologists. Admittedly, the output from some agent-based models is not so dissimilar (see Lake and Crema 2012 for an example) and it can certainly be argued (Premo 2007; also discussion in 
section 4.1) that more agent-based models should be published with phase diagrams denoting the results of systematic experimentation, but the overarching point stands: even if there is no necessary connection between the visual output of a model and its scientific utility, agent-based simulations can and frequently do capture the imagination of non-modellers in a way that other simulation techniques do not.

Second, moving backwards from outputs to inputs, agent-based modelling is also accessible in the sense that it does not enforce one particular way of specifying the rules which govern the behaviour of entities in the model: this can be done mathematically, but it can also be done purely algorithmically (e.g. Rubio-Campillo et al. 2011; Costopoulos 2001) or using artificial intelligence formalisms such as production rules (e.g. Doran et al. 1994; Reynolds 1987). The fact that agent-based modelling does not require the mathematical formality of dynamical systems modelling may well partly account for its greater uptake, since algorithmic rules are typically closer in form to the verbal specifications of informal models.

Third, agent-based modelling is accessible in the sense that it offers great flexibility with respect to what can be modelled. It has already been noted that while most agent-based models share certain paradigmatic features, not all these are necessary and others can be added. Thus, for example, agentbased models can employ models of space ranging from purely topological networks to geographically referenced representations of the earth's surface. Similarly, agents may be purely reactive (they behave) or they may be cognitive (they reason using their own models of what is in their environment), and they may or may not communicate with other agents (Ferber 1999). Section 1 of this chapter listed some examples which demonstrate how this flexibility allows archaeologists with quite different interests to make use of agent-based modelling.

Finally, although agent-based modelling is - as a technique - scale agnostic, in most archaeological examples the agents are ethnographic-scale, in other words, they represent individual human beings or small groups, such as households. In practice, then, agent-based simulation is accessible in the sense that it tends to realign computer simulation with both the commonsense lay notion that archaeology is about what people did in the past, as well as the more explicitly theorised objections to systemic thinking raised by proponents of post-processual archaeology (e.g. Shanks and Tilley 1987b). The interweaving of archaeological computer simulation and archaeological theory is teased out in reviews by Aldenderfer (1998), McGlade (2005) and Lake (2013), but particular points of contact between post-1980 archaeological theory and agent-based modelling include agreement that "historical processes involve the actions of self-aware individuals" (Kohler 2000, p.3) and the possibility of explicitly modelling cognition (Biskowski 1992; Doran 2000; Mithen 1989). That said, the detail of how agent-based models represent individuals and their relations with one another raises questions 
about the kind of rationality employed by agents (Lake 2004) and the locus of causality in human societies (Beekman 2005), and it is clear that some post-processual archaeologists (e.g. Thomas 1991, 2004) have not been won over on either count. Their concern, "Is is the world really agent-based?" (O'Sullivan and Haklay 2000), is discussed in more detail in section 3.

\subsection{Agent-based modelling as a scientific paradigm}

As just suggested, there are clear points of contact between agent-based modeling and important strands in post-1980 archaeological theory. This is very conspicuous in some studies, notably for example Mithen's Thoughtful Foragers, which provides a book-length manifesto for a cognitive-processual archaeology (Renfrew 1994), in this case grounded in behavioural ecology and realised with the aid of simulation. Mithen's focus on individual decision-making went some way to addressing post processual theorists' (see Dornan 2002, pp.308-314 for a review of the various positions taken) concern that the systemic perspective offered by processual archaeology overlooked the importance of individual agency and cognition (but see section 3.1), but at the same time, however, he retained a firm commitment to scientific inference by hypothesis-testing. Nevertheless, although the commitment to scientific inference and a broadly evolutionary approach is characteristic of the vast majority of agent-based models (Lake 2013), relatively few share both the ethnographic-scale and realism (in the sense of attempted closeness to actual human decision-making and choice of parameter values) of Mithen's model. Instead, most archaeological agent-based models are either more abstract, or are based on higher-level agents (such as households); they are also frequently concerned with longer-term change and the emergence of new phenomena. All this suggests that the uptake of agent-based modelling is better explained by archaeologists' interest in the wider scientific paradigm which spawned it rather than its fit with post 1980 archaeological theory per se.

As with the geographical information systems (GIS) 'tool or science' debate (Wright et al. 1997), it is important to recognise that, as a technique, agent-based modelling can be used for different purposes and in a variety of theoretical frameworks. Nevertheless, agent-based modelling is closely associated with complexity science (Waldrop 1992) ${ }^{1}$, whereas, for example, dynamical systems modelling is usually associated with chaos (Schuster 1988) and catastrophe theory (Zeeman 1977). Complexity science gained real momentum in the late 1980s / early 1990s and, although it builds on insights won by the formalisation of chaos and catastrophe in the 1960s and 1970s, it also marks a change of emphasis (Beekman and Baden 2005). The

\footnotetext{
${ }^{1}$ Although agent-based modelling also has semi-independent roots in ecological modelling, where, as individual-based modelling the initial focus was on the importance of organism heterogeneity and spatial localism (DeAngelis and Gross 1992, p.xv).
} 
mathematics of chaos provided tools to deal with the unpredictability and non-linearity of many real world processes, including some of obvious archaeological interest such as population growth (May 1976). Catastrophe theory ultimately proved more difficult to apply in the real world, but at minimum it reinforced the message that profound transformation does not necessarily require many factors working in tandem and nor does it necessarily require a strong external push (Renfrew and Poston 1979). Complexity science blends these insights with others from a different intellectual lineage that includes von Neumann's work on self-reproducing automata, cybernetics and connectionist cognitive science (Epstein and Axtell 1996, p.2) to focus on the emergence of macro-level properties from the mutual interaction of many micro-level parts, as well as the related question of how such systems learn (adapt). Unlike dynamical systems models, which normally work with variables representing aggregate phenomena (e.g. the number of individuals who have access to prestige goods - see McGlade 1997), agentbased models explicitly model the micro-level parts (as agents) and so are particularly well-suited to the complexity science agenda. Cellular automata share this particular property (the cells representing micro-level parts) and have also played a significant part in the development of complexity science (Toffoli and Margolus 1987; Wolfram 1984), but have found less use in archaeology as they are more restrictive in terms of the kinds of real-world phenomena they can represent (but see Mithen and Reed 2002 and Nikitas and Nikita 2005 for two archaeological applications of cellular automata).

The clearest manifestation of the impact of complexity science and agentbased modelling in the social sciences is the attempt to do what Epstein and Axtell (1996, p.177) have labelled generative social science. Their book Growing Artifical Societies demonstrates how agent-based modelling can be used to grow social phenomena in silico "from the bottom up". In the most basic version of their now famous model Sugarscape, the actions of agents pursuing individual goals (to harvest and consume 'sugar' deposited on a landscape) produce population-level phenomena such as a characterisic power-law wealth distribution and waves of advance across space. Following further experiments with versions of Sugarscape that include more 'human' elements, including sexual reproduction, cultural transmission, combat, exchange and disease, Esptein and Axtell conclude that "A wide range of important social, or collective, phenomena can be made to emerge from the spatio-temporal interaction of autonomous agents operating on landscapes under simple local rules" (ibid., p.153, my emphasis). Not only does this observation align social science with the interests of complexity science, but it also led Esptein and Axtell to propose a new model of explanation for the social sciences, one which they claim is neither deductive nor inductive, but 'generative': they interpret the question "can you explain it?" as asking "can you grow it?" (ibid., p.177) and thus they propose that explanation consists in "demonstrating that certain sets of microspecifications are suf- 
ficient to generate the macrophenomenon of interest" (ibid., p.20, original emphasis). On top of this epistemic move, Epstein and Axtell also argue that agent-based modelling provides the appropriate tool to overcome several specific deficiencies of contemporary social science: the use of local rather than global rules provides a "natural methodology for relaxing... assumptions" about the perfect rationality of actors (ibid., p.1); the possibility of agents having different characteristics overcomes the explicit or implicit suppression of agent heterogeneity; and the focus on dynamics overcomes preoccupation with static equilibria at the expense of exploring transitional states which might actually be more important or interesting (ibid., p.16). Overall, then, Epstein and Axtell hope that the agent-based approach will "yield a new, more unified and evolutionary social science, one in which migrations, demographic patterns, tribes, and tribal conflict, epidemics, markets, firms, institutions, and governments all emerge from the bottom up" (ibid., p162, original emphasis).

The Sugarscape agent-based model has been hugely influential: it is widely used for teaching computational social science and, within archaeology, is explicitly acknowledged as the inspiration for early examples of (modern) agent-based modelling such as the Long House Valley model (Axtell et al. 2002). Perhaps even more importantly, however, the very idea of generative social science has been gaining traction in archaeology. This is most obvious in writing that explicitly invokes Growing Artificial Societies, for example Kohler's (2000) manifesto for the potential of agent-based modelling to help with the task of "putting social sciences together again" and Premo's (2008, p.36) call to use agent-based models as "behavioural laboratories", but it also underwrites other statements of the principal that agent-based models should be generative (e.g. Costopoulos 2009, p.273). In fact, it can be argued that the majority of recent archaeological agent-based simulations adopt at least some aspects of the generative social science programme even if they do not explicitly invoke it. For example, many of the agent-based models designed to tackle problems in human evolution and/or evolutionary archaeology are concerned with emergence, the value of null models, or the less than perfect rationality of agents.

Premo's (2010) investigation of how a 'scatter and patches' archaeological landscape could have been produced by relatively simple Plio-Pleistocene hominin foraging and food-sharing behaviours is partly a study of an emergent phenomena. One could also argue that the models designed to demonstrate the effect of population size and structure on cultural trait diversity and cumulative innovation (e.g. Lake and Crema 2012; Powell et al. 2009; Premo 2012) also seek to explain how a population-level phenomenon, in this case cultural complexity, emerges from the interaction of agents.

Closely related to the notion of emergence is the realisation that complex patterns can be produced by the iteration of simple rules, which has in turn lead to recognition of the value of null models as a starting point of 
enquiry. Premo's aforementioned model of Plio-Pleistocene food-sharing is explicitly offered as null model (Premo 2007, p.34). More recently, Bentley and Ormerod have argued for the utility of models which assume "zerointelligence" (2012, pp.205-6) on the part of agents. Bentley and Ormerod do not think that real-world agents really have zero-intelligence, but given that complexity science suggests that "many of the emergent, often complex, patterns in society need not require complex behavior on the part of individuals" (ibid., p.205) they want to know how far we can get with simple social physics null models and what must be added to them to explain social phenomena. Bentley and colleagues have already demonstrated that a simple model of random copying is sufficient to explain the frequency distributions of cultural variants in first names, archaeological pottery, applications for technology patents, chosen dog breeds and popular music (Bentley et al. 2004, 2007).

As well as demonstrating the potential power of null models, the success of random copying models also reinforces our understanding that humans are not, in the main, perfectly rational decision-makers. In the context of null modelling this claim is usually predicated on the observation that humans do not have sufficient computational capacity to make optimal decisions and/or they do not have access to all the relevant information (e.g. Bentley and Ormerod 2012, pp.205-6). Exactly what is meant by rationality is further discussed in section 3.1, but the notion that humans are imperfect decision-makers because they only have access to spatially and/or temporally 'local' information has long been incorporated into archaeological agent-based models of hunter-gather foraging (see for example Reynolds 1987 and Mithen 1990); it is also now the explicit focus of enquiry in studies that seek to investigate the importance of noise (imperfect environmental tracking) in long-term adaptation (Xue et al. 2011).

Models such as those just cited demonstrate that the post-2000 uptake of agent-based modelling in archaeology has been accompanied by an interest in at least some strands of complexity science in general and generative social science in particular, even if it has not always been explicitly framed in those terms. While there are models which do not fit this characterisation so neatly, particularly tactical models (e.g. Rubio-Campillo et al. 2011), in the main there is a sense in which agent-based modelling has been adopted by archaeologists as both a technique and a scientific paradigm. It can be argued, however, that the particular strands of complexity science commonly found in archaeological agent-based models, such as relatively 'simple' emergent phenomena, the use of null models and a focus on limited rationality, reflect a particular perspective on complexity science, the Complex Adaptive Systems approach, that was strongly promoted by the Sante Fe Institute in the late 1980s and early 1990s. As Beekman and Baden (2005, p.7) rightly caution, the application of ideas from complexity science to social phenomena has a different emphasis in Europe, where there is greater interest in 
explicitly cognitive issues, including emotion and irrationality (Doran 2000) and, perhaps most importantly, a greater willingness to treat social systems as qualitatively different from other complex systems (Gilbert 1995). Although they note that "archaeologists working within this intellectual milieu have often chosen to use nonlinear concepts as metaphors to frame a verbal analysis rather than develop computer simulations" (ibid.) it is worth considering whether this is because textbook agent-based modelling, which is largely grounded in the Complex Adaptive Systems approach, carries with it particular - and perhaps debatable - assumptions about the way the world is?

\section{Ontological considerations: Emergence and ra- tionality}

As briefly alluded to above, the rapid deployment of GIS in a number of disciplines eventually led to debate about whether the technique is simply a tool that can be used for many purposes in a variety of theoretical frameworks, or whether it carries certain theoretical 'baggage' such that its use requires explicit or implicit adherence to particular theoretical principles or assumptions (in geography see Pickles 1999; Wright et al. 1997; in archaeology see Wheatley 1993; Gaffney and van Leusen 1995). Similar questions have been asked of agent-based modelling, although the anxiety seems less widespread and largely confined to two key issues: is the rationality of agents a good model of human rationality and in what sense do social phenomena emerge.

\subsection{The rationality of agents}

As has been documented elsewhere (Lake 2004) and remains true today, the agents in archaeological agent-based simulations have generally been ascribed a rationality that is grounded in either human biology (typically optimal foraging theory or evolutionary psychology), or modern economics. Some archaeologists have argued that the biological and/or economic grounding of agent rationality is undesirable as it projects modern rationality back into the past and precludes the possibility of discovering that the past really was different. Thus, directly addressing agent-based modelling, Thomas (1991, p.1) claimed that "The rationality which Mithen seeks to identify on the part of his Mesolithic foragers is a very specific one: it is the instrumental reason of late capitalism". In similar vein, but targeted at evolutionary archaeology more generally, Shanks and Tilley (1987a, p.56) expressed disquiet about recourse to either evolutionary biology or economics, since in their view the former leaves a "plastic, malleable cultural dope incapable of altering the conditions of his or her existence" (Shanks and Tilley 1987a, 
p.56) and the latter "naturalizes what are historically and culturally specific values as universal features of humanity" (Shanks and Tilley 1987b, p.188). The cultural specificity of rationality has also been emphasised by Cowgill, who claimed that "The allegedly universal rationality assumed by 'economic man' models is shown by anthropological knowledge to be the very opposite" (2000, p.55), and Clark who, comparing an approach to agency rooted in evolutionary theory with one rooted in practice theory, complained that "the individuals in optimal foraging models know more than real agents could know. Rational decisions require perfect knowledge of particulars and decision-making rules, which are cultural" (2000, p.108).

The central question here is not whether attributing to agents rationalities grounded in evolutionary biology or economics is appropriate (see Kohler 2000 and Mithen 1990 for arguments in favour of evolutionary biology as a source of agent rationality), but rather, whether agent-based simulation is limited to these kinds of rationality? In order to address this question, however, it is necessary to be clear what one means by rationality. The textbook view from artificial intelligence is that "A rational agent is one that does the right thing" (Russell and Norvig 2003, p.34), in other words, one "whose actions make sense from the point of view of the information possessed by the agent and its goals (or the task for which it was defined)" (Russell 1999, p.13). The important and perhaps surprising consequence of this (informal) definition is that "What counts in the first instance is what the agent does, not necessarily what it thinks, or even whether it thinks at all" (ibid, p.13). Thus the emphasis is first and foremost on what Simon (1956) termed substantive rationality - what decision to make-, rather than procedural rationality - how to make the decision. For the purposes of computation, substantive rationality is formalised through the agent function, which can be conceived as a table that records what action an agent performs as a result of a given percept sequence (a history of everything the agent has ever perceived). Procedural rationality is formalised through the agent program, which is the internal mechanism used by the agent to implement the agent function and which, in the case of a cognitive agent, will be some kind of reasoning process.

Archaeologists who criticise the rationality accorded to agents in agentbased models and/or evolutionary and computational approaches more generally are not always explicit about what they mean by rationality, or at least not in terms that allow direct comparison with the way rationality is understood in artificial intelligence. The necessary translation requires a detailed textual analysis, which falls outside the scope of this paper but I have attempted it elsewhere (Lake 2004, pp.195-197). I concluded that some critics (e.g. Clark 2000) are primarily concerned that the rationalities of past agents might need to be described by different agent functions, or as Clark put it, past agents "just have different motives" (ibid., p.101). Where that is the concern, there are no grounds for rejecting agent-based modelling since 
the technique does not require agent functions derived from either modern economic theory or evolutionary biology. Of course, it must be possible to state the agent function in a computer programming language, so in practice it may be easier to do this for economic and biologically grounded rationalities for the simple reason that we have explicitly theorised them, but in principle, there is no reason why agent-based simulations should necessarily project modern substantive rationality back into the past. On the other hand, other critics of computational and evolutionary archaeology (Cowgill 2000; Thomas 1991) extend their concern to the agent program, that is, how agents make decisions: for example, Thomas states that "Desires, emotions, forms of reason and techniques of self-interpretation are all contingent and historically situated" (Thomas 1991, p.17, my emphasis). Whereas one can in principle implement a wide range of agent functions in an agent-based model, it is less certain that agent programs are similarly unconstrained. Given that philosophers and artificial intelligence researchers are unable to agree about the limitations of machine intelligence (see Russell and Norvig 2003 , chapter 26 for a guide to the main arguments), it is simply not possible to guarantee that all forms of reasoning that humans have ever employed can be implemented on the computing devices currently available to us, never mind in an agent-based model implemented using the standard software tools. However, it is also notable that archaeologists who warn against projecting modern forms of reasoning back into the past do not themselves provide detailed descriptions of alternative forms which they believe were employed in specific contexts, quite possibly because they do not have a language adequate to that task. Consequently, while it may be that agent-based simulation imposes some (unknown) limits on models of past procedural rationality, an attempt to devise non-modern agent programs would at least provoke much-needed discussion about how to describe alternative forms of reasoning.

So far I have considered the kind of rationality exhibited by agents, but Thomas' critique of Mithen's agent-based model of Mesolithic hunting as having created a "cybernetic wasteland" (1988, p.64) extends to the argument that the agents in Mithen's model are unhuman because they are only rational and lack emotion. Mithen responded by acknowledging that emotional life is indeed "quintessentially human" (1991, p.10), but largely because it is wrong to counterpose emotion and reasoning, since emotions actually make rational thought possible by overcoming the problem of what to do in the face of conflicting goals and/or the impossibility of predicting the consequences of all available actions. Effectively, by drawing in this way on the cognitive and functional theories of emotion proposed by Oatley and Johnson-Laird (1987) and Frijda (Frijda 1987; Frijda and Swagerman 1987), Mithen simply proposes that emotions are implicitly included in models of adaptation via rational decision-making (Mithen 1991, p.9). Thus, while he argues that changes of state between, for example, stalking prey and killing 
it "are only made possible by emotions acting as a system of internal communication: monitoring the success and failure of sub-goals and the need to adjust behavioural plans" (ibid., p.13), it is not the case that any of the computer code in his agent-based model could have been omitted had he denied any role for emotion.

In partial contrast to Mithen's approach to the problem of incorporating emotion into agent-based modelling, there is a strand of artifical intelligence research which seeks to very explicitly model the role of emotion in cognition (Doran 2000). This research is still grounded in the 'functional view' (Frijda 1995) that emotions serve to aid decision-making (Cañamero and de Velde 2000, p.144), but in its most developed form it involves programming agents with a 'synthetic physiology', which includes variables necessary for survival (e.g. heart-rate, energy, blood sugar level) and hormones released under different emotional states which modify the amount of the controlled variables, thereby amplifying motives and thus ultimately influencing behaviour (Cañamero 1997). Thus, whereas the outcome of the emotional influence on rationality is completely predetermined in Mithen's model, this is not true in Cañamero's model, at least to the extent that the complexity of the interplay between emotions and reason may be sufficient to render it unpredictable in practice. If models like this really do offer the prospect of observing emotionally influenced behaviour that had not been explicitly imposed by the modeller then they open up the possibility of incorporating the role of emotion into the programme of generative social science. Indeed, Cañamero and Van de Velde (2000, p.148) describe at length a conceptual design for an agent-based model which would allow each agent some control over the expression of emotions according to its state, interests and the image it has of the other, so allowing emotional states to contribute to the construction of intersubjectivity (ibid., p.147). Although the bulk of research on agent emotion is situated within robotics (e.g. papers in Cañamero and Aylett 2008), the fact that at least some artificial intelligence researchers are prepared to entertain a social constructivist view of emotions (Averill 1990) makes it difficult to imagine what in-principle objection remains to the use of agent-based simulation to model human decision-making.

\subsection{The emergence of social phenomena}

As already noted, emergence is a central concept in complexity science and it is certainly the case that archaeologists have explicitly suggested that one of the benefits of using agent-based modelling is that it offers a means to study emergent phenomena. For example, Kohler and van der Leeuw suggest that agent-based models "enable us to examine the possibility of the emergence of new structures (for example, institutions, alliances, and communities) out of the basal units and their interactions" (2007a, p.6) and go on to emphasise the possibility of modelling the recursive relationship between the emergent 
structures and the underlying micro-level entities such that "the interaction between individuals create the society (and its culture), which in turn, affect the behaviour of the individuals or groups that constitute it" (ibid., p.7). Kohler also made a more specifically archaeological case for agent-based modeling: that the things we can measure in the archaeological record are on the one hand the outcome of agent behaviour "averaged over a great deal of space and time" but, given that, are also part of the "[context] within which agents make decisions and perform actions" (Kohler 2000, p.10). This again points to the idea that agent-based modelling can be used to disentangle an element of recursion, in this case between agents and their environment. It was suggested above that a significant number of archaeological agent-based models have been used to investigate emergence in some sense, but the key question here is in what sense exactly? This is a difficult question to answer because there is no widely accepted formal theory of emergence (Epstein and Axtell 1996, p.35) and indeed some would argue that the notion of emergence at best "remains vague and ill-defined" (Conte and Gilbert 1995, p.9) and at worst "seems opaque, and perhaps even incoherent" (Bedau and Humphreys 2008, p.1).

In philosophical debate the concept of emergence becomes entwined with fundamental problems such as the mind-body problem (Searle 1992), but in complexity science, and especially agent-based modelling, the term 'emergence' is most often used "to denote stable macroscopic patterns arising from the local interaction of agents" (Epstein and Axtell 1996, p.35). In the scheme proposed by the philosopher Bedau, cases of this kind of emergence are examples of either nominal emergence or weak emergence. Nominal emergence is the "simplest and barest" notion of emergence (Bedau 2008, p.158), one in which the emergent phenomena have the kinds of properties that cannot be micro properties. Thus, for example, Epstein and Axtell argue that the skewed wealth distribution produced by the Sugarscape model is an emergent phenomenon because "we do not know what it would mean for an agent to have a wealth distribution" (1996, p.35). In similar vein, it is possible to measure the pressure of a gas, but not the pressure of an individual molecule of that gas. The difference between nominal and weak emergence is that in the former the emergent properties can be predicted and explained from the properties of the individual micro-level entities, whereas in the case of weak emergence "the micro-level interactions are interwoven in such a complicated network that the global behaviour has no simple explanation" (Bedau 2008, p.160). In general, most of the agent based models developed under the banner of generative social science exhibit weak emergence. This is true of the archaeological models of Lake and Crema (2012), Powell et al. (2009) and Premo (2010; 2012) that were discussed earlier, and Beekman (2005, p.64) provides another list which supports this observation. Most of these models effectively demonstrate - whether explicitly or implicitly - that "many of the emergent, often complex, patterns in society 
need not require complex behavior on the part of individuals" (Bentley and Ormerod 2012, p.205), but on the other hand the interaction between individuals is often sufficiently complex (typically context dependent in some way) that it is not possible to predict the emergent phenomena except by running the simulation. This, of course, is what led Epstein and Axtell (1996, p.177) to argue that adequate explanation of many social phenomena consists in demonstrating the "generative sufficiency" of a model (but see section 4.1) for doubt about the adequacy of this proposition).

Despite the weight of actual modelling practice, there is considerable debate even within the modelling community about whether important social phenomena such as social institutions are the result of something more than weak emergence (Beekman 2005; Conte and Gilbert 1995; Gilbert 1995; Lake 2010; O'Sullivan and Haklay 2000). The two main issues are, first, whether at least some emergent social phenomena exert 'reverse' causal influence on agents (what Bedau labels strong emergence) and, second-but less discussed-whether it matters that human agents "are capable of reasoning, and do so routinely, about the emergent properties of their own societies" (Gilbert 1995, p.144).

The reality of reverse causal influence is a long-standing point of contention in sociology (see Gilbert 1995 for more detail). On the one hand, methdological holists follow in the footsteps of Durkheim and Parsons in according causal influence to supra-individual social entities. This could hardly be clearer than in Durkheim's definition of social facts as "ways of acting, thinking and feeling that are external to the individual and are endowed with a coercive power by virtue of which they exercise control over him" (Durkheim 2004, p.59). In similar vein, but much more recently, Kenneth Arrow argued that "social categories are used in economic analysis all the time and that they appear to be absolute necessities of the analysis, not just figures of speech that can be eliminated if need be" $(1994$, p.1). In contrast, methodological individualists (e.g. Watkins 1952; O'Meara 1997, Mithen 1990 in archaeology) take the view that "large-scale social phenomena must be accounted for by the situations, dispositions and beliefs of individuals" (Watkins 1952, p.58) and do not accept the ontological reality of social institutions, since even social roles "can be fully understood in terms of individuals as long as we take a wide enough perspective so as to include all those individuals, in other times and places, who create a role" (King 1999, p.216). The last three decades of the Twentieth Century saw numerous attempts to negotiate or even dissolve the micro-macro dichotomy in sociology (Beekman 2005, p.53). The most frequently cited in archaeology are Gidden's (1984) Structuration Theory and Bourdieu's (1977) Practice Theory, but in an article specifically examining the relationship between social theory and agent-based simulations, Beekman notes that the tendency among archaeologists to chose one or the other - along with the particular readings that have found their way into archaeology — has in practice ended 
up replicating the dichotomy between discursive strategizing action and nondiscursive practice that characterises the debate between methodological individualists and methodological holists (Beekman 2005, p.55). Noting that even individual human beings are emergent entities, Beekman's own preference is an approach grounded in - but not slavishly adhering too-Archer's (2000) critique of Structuration Theory (Beekman 2005, pp.62-3), which recognises multiple scales of collective "at which different rules of action predominate". He considers that collective agents are "real social entitites" (ibid., p.68) and although he does not explicitly say so, strongly implies that these entities exert reverse causal force on lower-level agents.

This is not the place to attempt to adjudicate between methodological holism, methodological individualism and attempts to overcome that dichotomy, but it is worth reiterating the point that actual practice in agent-based modelling tends towards methodological individualism (Beekman 2005; O'Sullivan and Haklay 2000). Even the few archaeological agentbased models that have explicitly modelled both individuals and groups (see Doran et al. 1994; Kohler et al. 2012b; Lake 2000) do not really exhibit the emergence of reverse causal force since in all cases the establishment of groups is scaffolded at the outset of the simulation. Consequently, it can be argued that, to date, the practice of archaeological agent-based simulation does not match Kohler and van der Leeuw's ambition to investigate the recursive relationship between individuals and society. Given the lack of unanimity among sociologists about the status of social institutions it is far from clear whether this really matters, especially given philosophical doubts about the ontological status of reverse causal force (e.g. see Bedau 2008, p.159, who argues that "strong emergence starts where scientific explanation ends"). That said, Gilbert makes the important point that if the definition of weak emergence hinges on the impossibility of analytically predicting the macro-level phenomena then "any particular emergent property stands the risk of being demoted from the status of emergence at some time in the future" (1995, p.150), which leads him to suggest that the relationship between micro and macro properties of complex systems may be more interesting than emergence per se. Following in this spirit there may at the very least be scope to use agent-based modelling to develop a better understanding of whether or how reverse causal force amounts to more than "feedback effects in the agent population, altering the behaviour of individuals" (Epstein and Axtell 1996, pp.16-7).

The second - albeit less discussed - issue in the debate about whether important social phenomena such as social institutions are the result of something more than weak emergence is the question of whether it matters that human agents reason about the emergent properties of their own societies. Some taxonomies of emergence do indeed distinguish between emergence that involves a degree of reflexivity and emergence that does not. For example, cognitive psychologist and artificial intelligence researcher Cristiano 
Castelfranchi has proposed four senses of emergence, of which the third is representational, meaning that the phenomenon in question is "learned or recognized at the cognitive level" (Conte and Gilbert 1995, p.9). In not disimilar vein, Sunny Auyang posits a three level hierarchy of complex systems in which the third is cybernetic systems that involve intentionality (Auyang 1998). Sociologist Nigel Gilbert clearly believes that failure to take account of the capacity of humans to "perceive, monitor and reason with the macroproperties of the society in which they live" (1995, p.155) undermines the utility of simulation for addressing the kinds of questions of interest to his discipline.

One potential difficulty with the argument that the reflexivity of humans gives rise to a special kind of emergence is that, although the human capacity to be reflexive is not contested, there is debate -including within archaeology (see Hodder 2001, p.10) — about the extent to which social practices are undertaken by agents who have practical knowledge, that is, who know "how to go on" in the world "as it is" without consciously reflecting upon it (Barrett 2001, p.151). This raises the spectre of a quantitative gradation (how much reflection is taking place) underpinning a qualitative distinction (a special kind of emergence). I suggest that Crutchfield's (2008) concept of intrinsic emergence may provide a solution to this conundrum. Crutchfield notes that in well-known physical examples of self-organizing phenomena (e.g. Rayleigh-Bénard convection cells in heated liquids) "the patterns which appear are detected by the observers and analysts" but, crucially, there is no reason to believe that those experiments behaved differently before the self-organizing phenomena were detected by scientists (ibid, p.271). Consequently, he argues that "it is the observer or analyst who lends the teleological 'self' to processes which otherwise simply 'organize' according to the underlying dynamical constraints" (ibid.). Crutchfield proposes that, in contrast, intrinsic emergence occurs when "the patterns formed confer additional functionality which supports global information processing" (ibid., p.272), or in other words, the system itself has 'discovered' the pattern. Significantly for our purposes, however, Crutchfield makes it clear that 'discovery' does not require a cognitive representation, but can be "[implicit] in the dynamics and behaviour of a process" if the system makes use of the new pattern (ibid.). Thus, the concept of intrinsic emergence may provide a means of recognising the reflexivity of social systems (albeit not necessarily just human systems) as something more profound than weak emergence, but without running into the problem of measuring the extent to which social practice is practical or discursive. 


\section{Epistemic considerations: how to learn by agent- based modelling}

Earlier it was suggested that archaeologists use computer simulation for one or more of four purposes: enforcing conceptual clarity, helping understand how things change, helping infer past behaviour from a static archaeological record, and testing other quantitative methods. The second and third of these are of particular interest here, since models built for understanding how things change and those built for infering past behaviour typically constitute the most fully worked through attempts to explain aspects of the human past. Within the archaeological simulation literature there is an established distinction between 'theory-building' and 'hypothesis-testing' models (e.g. Mithen 1994, pp.176-177), according to which the aim of hypothesis-testing models is to determine what actually happened in the past by comparing the output of a simulated process against the archaeological evidence, while the use of simulation models to support theory-building does not necessarily involve detailed comparison of output against the archaeological record since the purpose is not to test what happened in the past, but rather to understand how certain processes work and what sort of changes could plausibly have occurred. It can increasingly be questioned whether this is a particularly useful distinction, since, on the one hand, comparing simulation output with the archaeological evidence can contribute to theory-building (e.g. Kohler and Varien 2012), while on the other hand, simulation can be used to directly test hypotheses which are more about possible processes (e.g. the effect of parameters on model dynamics) than what actually happened in the past (see Premo 2010, pp.29-30). Rather than attempting to force models into a rigid taxonomy according to which each class represents a discrete inferential role, it seems more productive to focus attention on issues of modelling logic that commonly arise when attempting to learn by simulation.

\subsection{Learning by simulation requires experimentation not just emulation}

Earlier it was noted that the visual accessibility of many agent-based models may well be a significant factor in the rapidly growing popularity of the technique. Paradoxically, however, this same accessibility to non-specialists may also contribute to a lack of understanding that effective use of simulation requires an experimental approach. In a series of articles, Premo (2005; $2007 ; 2008$ ) has been particularly forceful in arguing that merely emulating the past does not explain it. The basic problem is relatively simple: by iteratively adjusting the process and/or parameters of a model it will probably be possible to obtain a reasonable fit between the model output and the archaeological evidence (an emulation), but this does not guarantee that 
only this process/parameters could have caused what happened in the past (the problem of equifinality) and nor does it provide a good understanding of the probability of this particular outcome versus others. Such underdetermination might not be a problem for those persuaded by constructive empiricism as an account of science, that is, the proposition that the aim of science is to produce theories that are empirically adequate rather than literally true (Fraassen 1980; see Kelley and Hanen 1988 for archaeological supporters), but it is a problem if one believes, as do most contemporary philosophers of science (Preston 2014), that scientific theories are literally either true or false, whether one can actually know that (as per scientific realism) or not (as per conjectural realism). It also casts some doubt on Epstein and Axtell's proposition that the programme of generative social science should equate explanation with answering the question "can you grow it?" (1996, p.177), since successfully 'growing' some phenomenon does not automatically overcome the problem of underdetermination - that there might be some other way of growing the same phenomenon.

Given that the significance of underdetermination is a major point of contention in the philosophy of science, it is hardly surprising that there is no simple solution for overcoming the problem of equifinality in archaeological inference. That said, computer simulation at least has the advantage that, if used as a "behavioural laboratory" (Premo 2008), it allows us to explicitly explore what alternative models might equally or better fit the observed phenomenon, and/or do so with less sensitivity to aspects of the model for which there is limited independent evidence. This requires two important moves. The first is that modelling starts with an explicit theory, in order that the prior understanding is rendered brittle enough by the need to maintain internal consistency that it can be broken, that is, found to be inadequate. The second move is to adopt an experimental exploratory design (ibid., p.49), one which does not simply attempt to replicate some observed phenomenon, but systematically explores the consequences of the model under a wide range of circumstances, only some of which may actually have obtained in the past. By re-running Gould's 'tape of history' (see Premo 2008, pp.49-50 for detailed discussion) in this way, the modeller can generate an ensemble of "what if' scenarios" (ibid., p.50) or "alternative cultural histories" (Gumerman and Kohler 2001) which can then provoke rejection of the model or form the basis of an explanation of the observed phenomenon in the sense of delineating what conditions must have been met for that phenomenon to have occurred if the model is correct.

Although appropriate experimental design is vital to productive use of simulation, two intrinsic properties of simulation models are also important: whether a model is generative and whether it is simple or complex. Each is considered in turn. 


\subsection{The most informative models are generative}

As discussed in section 2.3, the program of generative social science is built around a particular view of what constitutes an explanation. For Epstein and Axtell the aim of generative social science is "to provide initial microspecifications (initial agents, environments, and rules) that are sufficient to generate the macrostructures of interest" and thus they "consider a given macrostructure to be 'explained' by a given microspecification when the latter's generative sufficiency has been established" (1996, p.177). As noted above, it can be argued that this formulation takes insufficient account of underdetermination, but that does not detract from the point that explanation requires that the macrostructures of interest (e.g. social institutions or other population-level outcomes) must not have been programmed into the computer simulation at the outset, since were that the case then the model would simply describe a known outcome. As Costopoulos (2009, p.273) puts it, the explanatory power of a generative model lies in the fact that it "must be observed in operation to find out whether it will produce a predicted outcome".

While the power of generative modelling is widely acknowledged among simulation-using archaeologists (e.g. Beekman 2005; Costopoulos 2009; Kohler 2000; Premo 2008), its use does raise a practical problem of system-bounding if one is to avoid infinite regress. Thus, for example, Beekman (2005, p.66) has proposed that "the only rules that should be fixed within a simulation should be the most basic biological imperatives common to all humans, while any Giddensian structural rules and resources must emerge through agents' actions". While this may be appropriate if the purpose of the simulation is specifically to study how society 'works' (the context in which Beekman made this suggestion), it is less clear that one really needs to simulate the construction of the self and person sensu Simmel (see Scaff 2011, pp.213-225 and Archer 2000) in order to study, say, the effect of population size on the maintenance of cultural complexity, or how foraging in a patchy environment promotes food-sharing. Even sociologists who reject the ontological reality of social institutions accept that for practical purposes it may be necessary "to assume certain background conditions which are not reduced to their micro dimensions" (King 1999, p.223). It is important to recognise, however, that under these circumstances one can not claim that the model in any way explains the assumed macro-level properties. Thus, for example, although Lake's (2000) model of Mesolithic foraging was one of the relatively few early archaeological agent-based models which explicitly incorporated 'social' behaviour above the level of the basic agent (in this case collective decision-making by groups of family units), the model sought only to explain spatial outcomes of that decision-making, not the emergence or manner of the decision-making itself (see also commentary in O'Sullivan and Haklay 2000, p.1419). Ultimately, as Kohler and van der Leeuw remind us 
"A good model is not a universal scientific truth but fits some portion of the real world reasonably well, in certain respects and for some specific purpose" (2007b, p.3). Consequently, a pragmatic stance is that what matters is not whether a model is maximally generative, but whether it is generative with respect to its purpose, that is to say, it must incorporate agent-agent and agent-environment interaction relevant to its scale and it must be necessary to run the model in order to find out whether the particular phenomena of interest emerges.

\subsection{Explanatory power trades complexity against fit}

The issue of what is included in a model raises the question of whether models should be as simple as possible, or more 'lifelike'. As Levins (1966) long ago noted in the context of population modelling, it is in practice impossible to simultaneously maximise the generality, realism, and precision of models of complex systems. For some, this implies that choices must be made according to the intended scope and purpose of the model (Kohler and van der Leeuw 2007b, pp.7-8), whereas others see a strong presumption in favour of simplicity (Premo 2008, p.48).

There are three main arguments in favour of simplicity (which are not mutually exclusive). The first and most basic argument is that replicating a complex world by means of a complex model is unlikely to lead to enhanced understanding since the latter is achieved by reducing complexity to "intelligible dimensions" (Wobst 1974, p.151). In other words, explanation requires reduction, although whether that is more due to the limitations of the human intellect than it is a reflection of the way the world is has long been debated (see discussion on this point in Laird 1919, pp.342-4). Either way, Collard and Slingerland argue that in practice both scientists and humanists reduce, since "any truly interesting explanation of a given phenomenon is interesting precisely because it involves reduction of some sort - tracing causation from higher to lower levels or uncovering hidden causal relationships at the same level" (2012, location 311); indeed, they go so far as to suggest that "when someone fails to reduce we rightly dismiss their work as trivial, superficial, or uninformative" (ibid., location 314).

Not unrelated is the second argument in favour of simplicity: the application of the law of parsimony, which posits that one should adopt the simplest explanation for the observed facts. Indeed, one of the most important insights from complexity science is the discovery that complex macrolevel patterns do not necessarily require complex behaviour on the part of individual agents. As noted earlier, this has lead to enthusiasm for null modelling (Premo 2007), in which one starts by investigating how much of the observed phenomenon can be explained by the simplest possible model. Although it could be argued that complexity science adopts an ontological stance in favour of the notion that complexity is generated by the interac- 
tion of agents which individually exhibit relatively simple behaviour, null modelling can also be viewed as an epistemic move favouring the gradual addition of complexity to models to establish if doing so allows them to explain more of the patterning in the observed data (Premo 2007, p.34). Thus, for example, while Bentley and Ormerod argue "that the most appropriate 'null model' of individual behavior in larger societies is in fact... the 'zero-intelligence' model" (2012, pp.205-6), they also write at length about what needs to be added to a null model based on statistical physics precisely because human interactions are different. This may seem obvious, but the point of modelling "from the null-up" (Premo 2007, p.34) is to avoid making assumptions about complexity in favour of discovering how much complexity is necessary to explain the observed phenomenon. Kohler et al. (2012a, p.40) make a very similar point in relation to the use of optimizing models when they state that they "do not... want to predetermine the answer to fundamental questions such as, 'do societies operate so as to optimize the actions of their members?'-since these are questions we would like to ask".

The third argument in favour of simplicity is the argument from generality (e.g. Costopoulos 2009, p.275): that simpler models which have not been finely honed to fit a particular case, but can account for more - and more diverse - cases have greater explanatory power, not least because they allow one to predict what should happen in a wider range of circumstances and so obtain a greater sense of the likelihood of the observed phenomenon occurring rather than some other phenomenon. As Pinker forcefully argues, explanation requires more than "saying something just is": it consists in demonstrating "why it had to be that way as opposed to some other way it could have been" (Pinker 2002, p.72, my emphasis).

Although there are strong arguments in favour of keeping models simple, a common view among philosophers of science is that "the best model for a given data set is one which balances order and randomness by minimizing the model's size while simultaneously minimizing the 'amount of apparent randomness' " on the grounds that such a model ensures that "causes [are not] multiplied beyond necessity while also obtaining a good prediction" (Crutchfield 2008, p.274). In ecological modelling it is increasingly argued that the best way to find this "optimal zone of model complexity" is to build models that are structured to reproduce multiple real-world patterns, not least because it is thought that such models are usually less sensitive to parameter uncertainty (Grimm et al. 2005, p.989; also Piou et al. 2009). This approach may also be profitable in archaeology (Altaweel et al. 2010), but it is not unreasonable so suppose that the optimal balance between model size and fit may vary within a discipline which encompasses such wide-ranging subject-matter studied at a variety of spatial and temporal scales. For instance, minimizing apparent randomness may be important in a model designed to investigate whether Mesolithic land-use patterns on a small Scottish island reflect the exploitation of specific resources (Lake 2000), 
but on the other hand a more appropriate ambition for an archaeology of the very long-term might be whether there is an 'envelope of predictability' for major socio-environmental changes, within which specific events and timings remain unpredictable?" (Cornell et al. 2010, p.427). Ultimately then, it may be that models of varying simplicity and fit can be productive providing they meet two conditions: i) they are generative with respect to the problem at hand; and ii) they adopt an exploratory experimental design in order to elucidate other ways the explanandum could have been. In practice, such models are likely to be those at the simpler end of the spectrum, but this need not always be so.

\section{Summary}

Archaeologists have experimented with computer simulation for almost as long as they have used computers and even some of the earliest simulation models have features in common with contemporary agent-based models. Nevertheless, there has been an explosion of interest in agent-based simulation modelling since 2000, driven by its conceptual flexibility and accessibility, the appearance of relatively 'user-friendly' software and interest in the wider agenda of complexity science. Indeed it can be argued that the technique has now achieved a degree of maturity: its use in certain subdisciplines (e.g. evolutionary archaeology) is becoming literally unremarkable, such that papers increasingly focus on results and their implications for substantive problems rather than methodological issues. Even so, there is scope for greater consideration of what is required to maximise the potential of learning by simulation, particularly with regard to experimental design: ensuring that results are not 'built in' and achieving an appropriate balance between model complexity and the fit to data. Furthermore, there remain questions about what ontological baggage, if any, comes with the adoption of agent-based modelling. Many, if not most, archaeological agent-based models adopt a fairly strong methodological individualism and concomitantly weak notion of emergence. Is this why, or because, most archaeological agent-based models deal with small-scale societies? Is it just sensible scientific scepticism of mysterious downward causal forces, or is it a narrow-minded and premature closing down of the possibility of a scientific account of long-term social change? At present the answer is far from clear, but intelligent application of agent-based modelling to a more diverse range of problems will surely help to tease out what is required for satisfactory explanation of aspects of human history. 


\section{Acknowledgements}

I should like to thank Gabriel Wurzer and Kerstin Kowarik for inviting me to contribute to this volume and also for their hospitality in Vienna during the 2011 trans-disciplinary workshop Agents in Archaeology. I am also grateful to many others with whom I have debated the pros and cons of agent-based modelling and/or who have invited me to present or discuss agent-based models in various workshops and conferences over the years, notably: Ariane Burke, Mark Collard, Andre Costopoulos, Enrico Crema, Tim Kohler, Marco Madella, Steven Mithen, Luke Premo, Bernado Rondelli and James Steele.

\section{References}

Aldenderfer, M. S. (1981). Creating assemblages by computer simulation: the development and uses of ABSIM. In Sabloff, J. A., editor, Simulations in Archaeology, pages 11-49. University of New Mexico, Albuquerque.

Aldenderfer, M. S. (1998). Quantitative methods in archaeology: A review of recent trends and developments. Journal of Archaeological Research, 6:91-1220.

Allen, P. and McGlade, J. (1987). Evolutionary drive: the effect of microscopic diversity. Foundations of Physics, 17:723-738.

Allen, P. M., Strathern, M., and Baldwin, J. S. (2006). Evolutionary drive: new understandings of change in socio-economic systems. Emergence: Complexity and Organization, 8(2):2-19.

Altaweel, M., Alessa, L., Kliskey, A., and Bone, C. (2010). A framework to structure agent-based modeling data for social-ecological systems. Structure and Dynamics, 4(1):article 2.

Archer, M. (2000). Being Human: The Problem of Agency. Cambridge University Press, Cambridge.

Arrow, K. (1994). Methodological individualism and social knowledge. American Economic Review, 84(2):1-9.

Auyang, S. Y. (1998). Foundations of Complex-System Theories: In Economics, Evolutionary Biology, and Statistical Physics. Cambridge University Press, Cambridge.

Averill, J. R. (1990). A constructivist view of emotion. In Plutchik, R. and Kellerman, H., editors, Emotion: Theory, Research and Experience, Volume 1, pages pp.305-339. Academic Press, New York. 
Axtell, R. L., Epstein, J. M., Dean, J. S., Gumerman, G. J., Swedlund, A. C., Harburger, J., Chakravarty, S., Hammond, R., Parker, J., and Parker, M. (2002). Population growth and collapse in a multiagent model of the Kayenta Anasazi in Long House Valley. Proceedings of the National Academy of Sciences of the United States of America, 99(Suppl 3):72757279 .

Barrett, J. C. (2001). Agency, the duality of structure and the problem of the archaeological record. In Hodder, I., editor, Archaeological Theory Today, pages 141-164. Polity Press, Cambridge.

Barton, C., Ullah, I., and Mitasova, H. (2010a). Computational modeling and Neolithic socioecological dynamics: a case study from southwest Asia. American Antiquity, 75(2):364-386.

Barton, C. M. (2013). Stories of the past or science of the future? Archaeology and computational social science. In Bevan, A. and Lake, M., editors, Computational Approaches to Archaeological Spaces, pages 151-178. Left Coast Press, Walnut Creek, CA.

Barton, C. M., Ullah, I. I., and Bergin, S. (2010b). Land use, water and Mediterranean landscapes: modelling long-term dynamics of complex socio-ecological systems. Philosophical Transactions of the Royal Society A: Mathematical, Physical and Engineering Sciences, 368(1931):52755297 .

Bedau, M. A. (2008). Downward causation and autonomy in weak emergence. In Bedau, M. A. and Humphreys, P., editors, Emergence: Contemporary Readings in Philosophy and Science, pages 155-188. The MIT Press, Cambridge, MA.

Bedau, M. A. and Humphreys, P. (2008). Introduction. In Bedau, M. A. and Humphreys, P., editors, Emergence: Contemporary Readings in Philosophy and Science, pages 1-6. The MIT Press, Cambridge, MA.

Beekman, C. S. (2005). Agency, collectivities and emergence: Social theory and agent based simulations. In Beekman, C. S. and Baden, W. W., editors, Nonlinear Models for Archaeology and Anthropology, pages 5178. Ashgate, Aldershot, UK.

Beekman, C. S. and Baden, W. W. (2005). Continuing the revolution. In Beekman, C. S. and Baden, W. W., editors, Nonlinear Models for Archaeology and Anthropology, pages 1-12. Ashgate, Aldershot, UK.

Belovsky, G. E. (1987). Hunter-gatherer foraging: A linear programming approach. Journal of Anthropological Archaeology, 6(1):29-76. 
Bentley, A. and Ormerod, P. (2012). Agents, intelligence, and social atoms. In Collard, M. and Slingerland, E., editors, Creating Consilience: Reconciling Science and the Humanities, pages 205-222. Oxford University Press, Oxford.

Bentley, R., Lipo, C., Herzog, H., and Hahn, M. (2007). Regular rates of popular culture change reflect random copying. Evolution and Human Behavior, 28(3):151-158.

Bentley, R. A., Hahn, M. W., and Shennan, S. J. (2004). Random drift and culture change. Proceedings of the Royal Society of London B, 271:14431450 .

Bentley, R. A., Lake, M. W., and Shennan, S. J. (2005). Specialisation and wealth inequality in a model of a clustered economic network. Journal of Archaeological Science, 32:1346-1356.

Binford, L. R. (1981). Bones: Ancient Men and Modern Myths. Academic Press, New York.

Biskowski, M. (1992). Cultural change, the prehistoric mind, and archaeological simulations. In Reilly, P. and Rahtz, S., editors, Archaeology and the Information Age, pages 212-229. Routledge, London.

Bourdieu, P. (1977). Outline of a Theory of Practice. Cambridge University Press, Cambridge.

Cañamero, D. (1997). Modeling motivations and emotions as a basis for intelligent behaviour. In Johnson, W. L., editor, Proceedings of the First International Conference on Autonomous Agents, pages pp.148-155. ACM Press, New York.

Cañamero, D. and de Velde, W. V. (2000). Emotionally grounded social interaction. In Dautenhahn, K., editor, Human Cognition and Social Agent Technology, pages 137-162. John Benjamins Publishing Company, Amsterdam.

Cañamero, L. and Aylett, R., editors (2008). Animating Expressive Characters for Social Interaction. John Benjamins Publishing Company, Amsterdam.

Ch'ng, E. (2007). Using games engines for archaeological visualisation: Recreating lost worlds. In Proceedings of CGames 2007 (11th International Conference on Computer Games: AI, Animation, Mobile, Educational 85 Serious Games), La Rochelle, France (2007), volume 7, pages $26-30$. 
Ch'ng, E., Chapman, H., Gaffney, V., Murgatroyd, P., Gaffney, C., and Neubauer, W. (2011). From sites to landscapes: How computing technology is shaping archaeological practice. Computer, 44(7):40-46.

Clark, J. E. (2000). Towards a better explanation of hereditary inequality: A critical assessment of natural and historic human agents. In Dobres, M.-A. and Robb, J. E., editors, Agency in Archaeology, pages 92-112. Routledge, London.

Clarke, D. L., editor (1972). Models in Archaeology. Methuen, London.

Conte, R. and Gilbert, N. (1995). Introduction: Computer simulation for social theory. In Gilbert, N. and Conte, R., editors, Artificial Societies: The Computer Simulation of Social Life, pages 1-18. UCL Press, London.

Cornell, S., Costanza, R., Sörlin, S., and van der Leeuw, S. (2010). Developing a systematic "science of the past" to create our future. Global Environmental Change, 20(3):426-427.

Costopoulos, A. (2001). Evaluating the impact of increasing memory on agent behaviour: Adaptive patterns in an agent-based simulation of subsistence. Journal of Artificial Societies and Social Simulation, 4. http://www. soc.surrey.ac.uk/JASSS/4/4/7.html.

Costopoulos, A. (2009). Simulating society. In Maschner, H., Bentley, R. A., and Chippindale, C., editors, Handbook of Archaeological Theories, pages 273-281. Altamira Press, Lanham, Maryland.

Cowgill, G. E. (2000). "Rationality" and contexts in agency theory. In Dobres, M.-A. and Robb, J. E., editors, Agency in Archaeology, pages 51-60. Routledge, London.

Crema, E. R. (2013). A simulation model of fission-fusion dynamics and long-term settlement change. Journal of Archaeological Method and Theory. DOI: $10.1007 / \mathrm{s} 10816-013-9185-4$.

Crutchfield, J. P. (2008). Is anything ever new? Considering emergence. In Bedau, M. A. and Humphreys, P., editors, Emergence: Contemporary Readings in Philosophy and Science, pages 269-286. MIT Press, Cambridge, MA. Originally published in Cowan, Pines and and Meltzer eds, 1999, Complexity: Metaphors, Models and Reality, Westview Press.

Dean, J. S., Gumerman, G. J., Epstein, J. M., Axtell, R. L., Swedlund, A. C., Parker, M. T., and McCarroll, S. (2000). Understanding Anasazi culture change through agent-based modeling. In Kohler, T. A. and Gumerman, G. J., editors, Dynamics in Human and Primate Societies: Agent-Based Modelling of Social and Spatial Processes, Santa Fe Institute Studies in 
the Sciences of Complexity, pages 179-205. Oxford Univesity Press, New York.

DeAngelis, D. L. and Gross, L. J. (1992). Individual-Based Models and Approaches in Ecology: Populations, Communities and Ecosystems. Chapman \& Hall, New York.

Doran, J. E. (1970). Systems theory, computer simulations, and archaeology. World Archaeology, 1:289-98.

Doran, J. E. (2000). Trajectories to complexity in artificial societies: Rationality, belief and emotions. In Kohler, T. A. and Gumerman, G. J., editors, Dynamics in Human and Primate Societies: Agent-Based Modelling of Social and Spatial Processes, pages 89-144. Oxford University Press, New York.

Doran, J. E. and Hodson, F. R. (1975). Mathematics and Computers in Archaeology. Edinburgh University Press, Edinburgh.

Doran, J. E. and Palmer, M. (1995). The EOS project: Integrating two models of Palaeolithic social change. In Gilbert, N. and Conte, R., editors, Artificial Societies: The Computer Simulation of Social Life, pages 103125. UCL Press, London.

Doran, J. E., Palmer, M., Gilbert, N., and Mellars, P. (1994). The EOS project: Modelling Upper Palaeolithic social change. In Gilbert, N. and Doran, J., editors, Simulating Societies, pages 195-221. UCL Press, London.

Dornan, J. L. (2002). Agency and archaeology: Past, present, and future directions. Journal of Archaeological Method and Theory, 9(4):303-329.

Durkheim, E. (2004). Readings from Emile Durkheim. Routledge, New York. Edited by Kenneth Thompson.

Eerkens, J. W., Bettinger, R. L., and McElreath, R. (2005). Cultural transmission, phylogenetics, and the archaeological record. In Lipo, C. P., O'Brien, M. J., Collard, M., and Shennan, S. J., editors, Mapping Our Ancestors: Phylogenic Methods in Anthropology and Prehistory, pages 169-183. Transaction Publishers, Somerset, NJ.

Epstein, J. M. and Axtell, R. (1996). Growing Artificial Societies: Social Science from the Bottom Up. Brookings Press and MIT Press, Washington.

Ferber, J. (1999). Multi-Agent Systems: An Introduction to Distributed Artificial Intelligence. Addison-Wesley, Harlow, England, english edition. 
Fraassen, B. (1980). The Scientific Image. Clarendon Press, Oxford.

Frijda, N. H. (1987). The Emotions. Cambridge University Press, Cambridge.

Frijda, N. H. (1995). Emotions in robots. In Roitblat, H. L. and Meyer, J.-A., editors, Comparative Approaches to Cognitive Science, pages pp.501-516. MIT Press, Cambridge, Massachusetts.

Frijda, N. H. and Swagerman, J. (1987). Can computers feel? Theory and design of an emotional system. Cognition and Emotions, 1:235-257.

Gaffney, V. and van Leusen, P. M. (1995). Postscript-GIS, environmental determinism and archaeology: A parallel text. In Lock, G. R. and Stančič, Z., editors, Archaeology and Geographical Information Systems: a European Perspective, pages 367-382. Taylor \& Francis, London.

Giddens, A. (1984). The Constitution of Society: Outline of a Theory of Structuration. Polity Press, Cambridge.

Gilbert, N. (1995). Emergence in social simulation. In Gilbert, N. and Conte, R., editors, Artificial Societies: The Computer Simulation of Social Life, pages 144-156. U.C.L. Press, London.

Gilbert, N. (2008). Agent-Based Models. Quantitative applications in the social sciences. Sage, Thousand Oaks, CA.

Gould, S. J. (1989). Wonderful Life: The Burgess Shale and the Nature of History. Vintage, London, paperback edition.

Grimm, V. and Railsback, S. (2005). Individual-Based Modeling and Ecology. Princeton University Press, Princeton.

Grimm, V., Revilla, E., Berger, U., Jeltsch, F., Mooij, W. M., Railsback, S. F., Thulke, H.-H., Weiner, J., Wiegand, T., and DeAngelis, D. L. (2005). Pattern-oriented modeling of agent-based complex systems: lessons from ecology. Science, 310(5750):987-991.

Gumerman, G. J. and Kohler, T. A. (2001). Creating alternative cultural histories in the prehistoric Southwest: Agent-based modelling in archaeology. In Examining the Course of Southwest Archaeology: The Durango Conference, September 1995, pages 113-124. New Mexico Archaeological Council, Albuquerque.

Hodder, I. (2001). Introduction: A review of contemporary theoretical debates in archaeology. In Hodder, I., editor, Archaeological Theory Today, pages 1-13. Polity Press, Cambridge. 
Innis, G. S. (1972). Simulation of ill-defined systems, some problems and progress. Simulation, 19:33-36.

Johnson, C. D. and Kohler, T. A. (2012). Modeling plant and animal productivity and fuel use. In Kohler, T. A., Varien, M. D., and Wright, A. M., editors, Emergence and Collapse of Early Villages: Models of Central Mesa Verde Archaeology, pages 113-128. University of California Press, Berkeley.

Kachel, A. F., Premo, L. S., and Hublin, J.-J. (2011). Grandmothering and natural selection. Proceedings of the Royal Society B: Biological Sciences, 278(1704):384-391.

Kelley, J. H. and Hanen, M. P. (1988). Archaeology and the Methodology of Science. University of New Mexico Press, Albuquerque.

King, A. (1999). Against structure: a critique of morphogenetic social theory. The Sociological Review, 47(2):199-227.

Kobti, Z. (2012). Simulating household exchange with cultural algorithms. In Kohler, T. A. and Varien, M. D., editors, Emergence and collapse of early villages: models of central Mesa Verde archaeology, pages 165-174. University of California Press, Berkeley.

Kohler, T. A. (2000). Putting social sciences together again: An introduction to the volume. In Kohler, T. A. and Gumerman, G. J., editors, Dynamics in Human and Primate Societies: Agent-Based Modelling of Social and Spatial Processes, Santa Fe Institute Studies in the Sciences of Complexity, pages 1-44. Oxford University Press, New York.

Kohler, T. A., Bocinsky, R. K., Cockburn, D., Crabtree, S. A., Varien, M. D., Kolm, K. E., Smith, S., Ortman, S. G., and Kobti, Z. (2012a). Modelling prehispanic Pueblo societies in their ecosystems. Ecological Modelling, 241:30-41.

Kohler, T. A., Cockburn, D., Hooper, P. L., Bocinsky, R. K., and Kobti, Z. (2012b). The coevolution of group size and leadership: an agent-based public goods model for prehispanic Pueblo societies. Advances in Complex Systems, 15(1 \& 2):1150007-1-1150007-29.

Kohler, T. A. and Gumerman, G. J., editors (2000). Dynamics in Human and Primate Societies: Agent Based Modeling of Social and Spatial Processes. Oxford University Press, Oxford.

Kohler, T. A., Gumerman, G. J., and Reynolds, R. G. (2005). Simulating ancient societies. Scientific American, 293:76-84. 
Kohler, T. A., Kresl, J., West, C. V., Carr, E., and Wilshusen, R. H. (2000). Be there then: A modeling approach to settlement determinants and spatial efficiency among Late Ancestral Pueblo populations of the Mesa Verde region, U.S. Southwest. In Kohler, T. A. and Gumerman, G. J., editors, Dynamics in Human and Primate Societies, Santa Fe Institute Studies in the Sciences of Complexity, pages 145-178. Oxford University Press, New York.

Kohler, T. A. and van der Leeuw, S. E. (2007a). Introduction: Historical socionatural systems and models. In Kohler, T. A. and van der Leeuw, S. E., editors, The Model-Based Archaeology of Socionatural Systems, pages 112. School for Advanced Research Press, Santa Fe.

Kohler, T. A. and van der Leeuw, S. E., editors (2007b). The Model-Based Archaeology of Socionatural Systems. School for Advanced Research Press, Santa Fe.

Kohler, T. A. and Varien, M. D. (2012). Emergence and collapse of early villages in the central Mesa Verde: An introduction. In Emergence and Collapse of Early Villages in the Central Mesa Verde: Models of Central Mesa Verde Archaeology, pages 1-14. University of California Press, Berkeley.

Kolm, K. E. and Smith, S. M. (2012). Modeling paleohydrological system strucure and function. In Kohler, T. A., Varien, M. D., and Wright, A. M., editors, Emergence and Collapse of Early Villages: Models of Central Mesa Verde Archaeology, pages 73-83. University of California Press, Berkeley.

Laird, J. (1919). The law of parsimony. The Monist, 29(3):321-344.

Lake, M. W. (2000). MAGICAL computer simulation of Mesolithic foraging. In Kohler, T. A. and Gumerman, G. J., editors, Dynamics in Human and Primate Societies: Agent-Based Modelling of Social and Spatial Processes, pages 107-143. Oxford University Press, New York.

Lake, M. W. (2001a). Numerical modelling in archaeology. In Brothwell, D. R. and Pollard, A. M., editors, Handbook of Archaeological Sciences, pages 723-732. John Wiley \& Sons, Chichester.

Lake, M. W. (2001b). The use of pedestrian modelling in archaeology, with an example from the study of cultural learning. Environment and Planning B: Planning and Design, 28:385-403.

Lake, M. W. (2004). Being in a simulacrum: Electronic agency. In Gardner, A., editor, Agency Uncovered: Archaeological Perspectives on Social Agency, Power and Being Human, pages 191-209. UCL Press, London. 
Lake, M. W. (2010). The uncertain future of simulating the past. In Costopoulos, A. and Lake, M., editors, Simulating Change: Archaeology into the Twenty-First Century, pages 12-20. University of Utah Press., Salt Lake City.

Lake, M. W. (2013). Trends in archaeological simulation. Journal of Archaeological Method and Theory. DOI: 10.1007/s10816-013-9188-1.

Lake, M. W. and Crema, E. R. (2012). The cultural evolution of adaptivetrait diversity when resources are uncertain and finite. Advances in Complex Systems, 15(1 \& 2):1150013-1-1150013-19.

Levins, R. (1966). The strategy of model building in population biology. American scientist, 54(4):421-431.

May, R. M. (1976). Simple mathematical models with very complicated dynamics. Nature, 261:459-467.

McGlade, J. (1995). Archaeology and the ecodynamics of human-modified landscapes. Antiquity, 69:113-132.

McGlade, J. (1997). The limits of social control: Coherence and chaos in a prestige-goods economy. In van der Leeuw, S. E. and McGlade, J., editors, Time, Process and Structured Transformation in Archaeology, pages 298330. Routledge, London.

McGlade, J. (2005). Systems and simulacra: Modeling, simulation, and archaeological interpretation. In Maschner, H. D. G. and Chippindale, C., editors, Handbook of archaeological methods, pages 554-602. Altamira Press, Oxford.

Mithen, S. and Reed, M. (2002). Stepping out: A computer simulation of hominid dispersal from Africa. Journal of Human Evolution, 43:433-462.

Mithen, S. J. (1987). Modelling decision making and learning by low latitude hunter gatherers. European Journal of Operational Research, 30(3):240242.

Mithen, S. J. (1988). Simulation as a methodological tool: Inferring hunting goals from faunal assemblages. In Ruggles, C. L. N. and Rahtz, S. P. Q., editors, Computer Applications and Quantitative Methods in Archaeology 1987, number 393 in International Series, pages 119-137. British Archaeological Reports.

Mithen, S. J. (1989). Modeling hunter-gatherer decision making: Complementing optimal foraging theory. Human Ecology, 17:59-83.

Mithen, S. J. (1990). Thoughtful Foragers: A Study of Prehistoric Decision Making. Cambridge University Press, Cambridge. 
Mithen, S. J. (1991). 'A cybernetic wasteland'? Rationality, emotion and Mesolithic foraging. Proceedings of the Prehistoric Society, 57:9-14.

Mithen, S. J. (1994). Simulating prehistoric hunter-gatherers. In Gilbert, N. and Doran, J., editors, Simulating Societies: The Computer Simulation of Social Phenomena, pages 165-193. UCL Press, London.

Nikitas, P. and Nikita, E. (2005). A study of hominin dispersal out of Africa using computer simulations. Journal of Human Evolution, 49:602-617.

Oatley, K. and Johnson-Laird, P. (1987). Towards a cognitive theory of emotions. Cognition and Emotions, 1:1-29.

Odling-Smee, F. J., Laland, K. N., and Feldman, M. W. (2003). Niche Construction: The Neglected Process in Evolution. Princeton University Press, Princeton, New Jersey.

O'Meara, T. (1997). Causation and the struggle for a science of culture. Current Anthropology, 38(3):399-418.

Orton, C. (1982). Computer simulation experiments to assess the performance of measures of quantity of pottery. World Archaeology, 14:1-19.

O'Sullivan, D. and Haklay, M. (2000). Agent-based models and individualism: Is the world agent-based? Environment and Planning A, 32:14091425 .

Pickles, J. (1999). Arguments, debates, and dialogues: The GIS-social theory debate and the concern for alternatives. In Longley, P. A., Goodchild, M. F., Maguire, D. J., and Rhind, D. W., editors, Geographical Information Systems: Principles, Techniques, Applications, and Management, pages 49-60. John Wiley \& Sons, New York.

Pinker, S. (2002). The Blank Slate: The Modern Denial of Human Nature. Viking, New York.

Piou, C., Berger, U., and Grimm, V. (2009). Proposing an information criterion for individual-based models developed in a pattern-oriented modelling framework. Ecological Modelling, 220(17):1957-1967.

Powell, A., Shennan, S., and Thomas, M. G. (2009). Late Pleistocene demography and the appearance of modern human behavior. Science, 324:12981301.

Premo, L. S. (2005). Patchiness and prosociality: An agent-based model of Plio/Pleistocene hominid food sharing. In Davidsson, P., Takadama, K., and Logan, B., editors, MABS 2004, volume 3415 of Lecture Notes in Artificial Intelligence, pages 210-224. Springer-Verlag, Berlin. 
Premo, L. S. (2007). Exploratory agent-based models: Towards an experimental ethnoarchaeology. In Clark, J. T. and Hagemeister, E. M., editors, Digital Discovery: Exploring New Frontiers in Human Heritage. CAA 2006. Computer Applications and Quantitative Methods in Archaeology, pages 29-36. Archeolingua Press, Budapest.

Premo, L. S. (2008). Exploring behavioral terra incognita with archaeological agent-based models. In Frischer, B. and Dakouri-Hild, A., editors, Beyond Illustration: 2D and 3D Technologies as Tools of Discovery in Archaeology, British Archaeological Reports International Series, pages 46-138. ArchaeoPress, Oxford.

Premo, L. S. (2010). Equifinality and explanation: The role of agent-based modeling in postpositivist archaeology. In Costopoulos, A. and Lake, M., editors, Simulating Change: Archaeology into the Twenty-First Century, pages 28-37. University of Utah Press, Salt Lake City.

Premo, L. S. (2012). Local extinctions, connectedness, and cultural evolution in structured populations. Advances in Complex Systems, 15(1\&2):1150002-1-1150002-18.

Premo, L. S., Murphy, J. T., Scholnick, J. B., Gabler, B., and Beaver, J. (2005). Making a case for agent-based modeling. Society for Archaeological Sciences Bulletin, 28(3):11-13.

Premo, L. S. and Scholnick, J. B. (2011). The spatial scale of social learning affects cultural diversity. American antiquity, 76(1):163-176.

Preston, J. (2014). Positivist and post-positivist philosophy of science. In Oxford Handbook of Archaeological Theory. Oxford University Press, Oxford.

Railsback, S. F. and Grimm, V. (2012). Agent-Based and Individual-Based Modeling: A Practical Introduction. Princeton University Press, Princeton.

Renfrew, A. C. (1981). The simulator as demiurge. In Sabloff, J. A., editor, Simulations in Archaeology, pages 283-306. University of New Mexico Press, Albuquerque.

Renfrew, C. (1994). Towards a cognitive archaeology. In Renfrew, C. and Zubrow, E. B. W., editors, The Ancient Mind: Elements of a Cognitive Archaeology, pages 3-12. Cambridge University Press, Cambridge.

Renfrew, C. and Poston, T. (1979). Discontinuities in the endogeneous change of settlement pattern. In Transformations: Mathematical Approaches to Culture Change, pages 437-461. Academic Press, New York. 
Reynolds, R. G. (1987). A production system model of hunter-gatherer resource scheduling adaptations. European Journal of Operational Research, 30(3):237-239.

Rubio-Campillo, X., María Cela, J., and Hernàndez Cardona, F. (2011). Simulating archaeologists? Using agent-based modelling to improve battlefield excavations. Journal of Archaeological Science, 39:347-356.

Russell, S. (1999). Rationality and intelligence. In Woolridge, M. and Rao, A., editors, Foundations of Rational Agency, pages 11-33. Kluwer Academic Publishers, Dordrecht.

Russell, S. and Norvig, P. (2003). Artificial Intelligence: A Modern Approach. Pearson Education, Upper Saddle River, New Jersey, 2nd edition.

Scaff, L. A. (2011). Georg Simmel. In The Wiley-Blackwell Companion to Major Social Theorists, Volume 1. Blackwell Publishing Ltd., Chichester.

Schuster, H. G. (1988). Deterministic Chaos. VCH Publishers, New York.

Searle, J. (1992). The Rediscovery of the Mind, chapter Reductionsim and the Irreducibility of Consciousness. MIT Press, Cambridge, MA.

Shanks, M. and Tilley, C. (1987a). Re-Constructing Archaeology. University Press, Cambridge.

Shanks, M. and Tilley, C. (1987b). Social Theory and Archaeology. Polity Press, Cambridge.

Simon, H. A. (1956). Rational choice and the structure of the environment. Psychological Review, 63(2):129-138.

Slingerland, E. and Collard, M. (2012). Introduction. creating consilience: Toward a second wave. In Slingerland, E. and Collard, M., editors, Creating Consilience: Integrating the Sciences and Humanities, pages location 123-740 (e-edition). Oxford University Press.

Surovell, T. and Brantingham, P. (2007). A note on the use of temporal frequency distributions in studies of prehistoric demography. Journal of Archaeological Science, 34(11):1868-1877.

Thomas, D. H. (1972). A computer simulation model of Great Basin Shoshonean subsistance and settlement. In Clarke, D. L., editor, Models in Archaeology, pages 671-704. Methuen, London.

Thomas, J. (1988). Neolithic explanations revisited: The MesolithicNeolithic transition in Britain and south Scandinavia. Proceedings of the Prehistoric Society, 54:59-66. 
Thomas, J. (1991). The hollow men? a reply to Steven Mithen. Proceedings of the Prehistoric Society, 57:15-20.

Thomas, J. (2004). Archaeology and Modernity. Routledge, London.

Toffoli, T. and Margolus, N. (1987). Cellular Automata Machine: A New Environment for Modeling. MIT Press, Cambridge, MA.

van der Leeuw, S. and Redman, C. L. (2002). Placing archaeology at the center of socio-natural studies. American Antiquity, 67(4):597-605.

van der Leeuw, S. E. (2008). Climate and society: Lessons from the past 10000 years. AMBIO: A Journal of the Human Environment, 37(sp14):476-482.

Waldrop, M. (1992). Complexity: The Emerging Science at the Edge of Order and Chaos. Simon \& Schuster, New York.

Watkins, J. W. N. (1952). Ideal types and historical explanation. British Journal for the Philosophy of Science, 3:22-43.

Watson, P. J., LeBlanc, S. A., and Redman, C. (1971). Explanation in Archaeology: An Explicitly Scientific Approach. Columbia Univesity Press, New York.

Wheatley, D. (1993). Going over old ground: GIS, archaeological theory and the act of perception. In Andresen, J., Madsen, T., and Scollar, I., editors, Computing the Past: Computer Applications and Quantitative Methods in Archaeology 1992, pages 133-138. Aarhus University Press, Aarhus.

Wilkinson, T., Christiansen, J., Ur, J., Widell, M., and Altaweel, M. (2007). Urbanization within a dynamic environment: modeling Bronze Age communities in upper Mesopotamia. American Anthropologist, 109(1):52-68.

Wobst, H. M. (1974). Boundary conditions for Palaeolithic social systems: A simulation approach. American Antiquity, 39:147-178.

Wobst, H. M. (2010). Discussant's comments, Computer Simulation Symposium, Society for American Archaeology. In Costopoulos, A. and Lake, M., editors, Simulating Change: Archaeology into the Twenty-First Century, pages 9-11. University of Utah Press, Salt Lake City.

Wolfram, S. (1984). Cellular automata as models of complexity. Nature, 311:419-424.

Wright, D. J., Goodchild, M. F., and Proctor, J. D. (1997). Demystifying the persistent ambiguity of GIS as "tool" versus "science". The Annals of the Association of American Geographers, 87:346-362. Also available from http://dusk.geo.orst.edu/annals.html (accessed 11/10/2004). 
Wright, H. T. and Zeder, M. (1977). The simulation of a linear exchange system under equilibrium conditions. In Earle, T. K. and Ericson, J. E., editors, Exchange Systems in Prehistory, pages 233-253. Academic Press, New York.

Xue, J. Z., Costopoulos, A., and Guichard, F. (2011). Choosing fitnessenhancing innovations can be detrimental under fluctuating environments. PloS one, 6(11):e26770.

Zeeman, E. C., editor (1977). Readings in Catastrophe Theory. AddisonWesley, Reading, Mass.

Zubrow, E. (1981). Simulation as a heuristic device in archaeology. In Sabloff, J. A., editor, Simulations in Archaeology, pages 143-188. University of New Mexico Press, Albuquerque. 